\title{
Spray Parametric Determination and Testing of anAnimal Drawn Wheel-Axle CDA Boom Sprayer
}

\author{
${ }^{1}$ Michael C. Amonye, ${ }^{1}$ M. L. Suleiman, ${ }^{1}$ Abdullahi El-Okene, ${ }^{2}$ Ibrahim O. \\ Abdulmalik \\ ${ }^{1}$ Institute for Agricultural Research (IAR), Department of Agricultural Engineering, Ahmadu Bello University, \\ Samaru, Zaria. \\ ${ }^{2}$ Hydraulic Equipment Development Institute, National Agency for Science and Engineering Infrastructure \\ (NASENI), Federal Ministry of Science and Technology, P.M.B 3067, Kano Nigeria.
}

\begin{abstract}
Assorted techniques have been developed for warring against pests, but the most important innovation appears to be the use of chemicals which are now available for different pest situations. Many manual and motorized machines have been developed for crop protection. In Nigeria and especially in farming communities of the north, attempts have been geared towards the development of requisite animal drawn machines for on-farm spraying against pests.

A ground metering Animal Drawn Controlled Droplet Applicator (CDA) Shrouded Disc Sprayer which ground metering is actuated by a wheel axle mechanism was designed and developed at the Institute for Agricultural Research (IAR) workshop, Department of Agricultural Engineering, Ahmadu Bello University, Zaria. It was tested on a farm and the ground metering through an axle mechanism was found to be very operationally efficient. During the course of its development laboratory and workshop tests were carried out to determine the optimum spray height and nozzle spacingfor uniform distribution of herbicide. The values were $30 \mathrm{~cm}$, and $1.25 \mathrm{~m}$ respectively. The pump discharge and boom swath as well as the application rate $(\mathrm{l} / \mathrm{ha}$ ) were also obtained. The equipment was constructed employing the spray components at the determined parameters and was consequently tested on the field.
\end{abstract}

Key Words: Pests, farm, spraying, machine, evaluation.

\section{Introduction:}

Weeds are the second most significant agricultural problem, second only to soil erosion. The fact is that growers must control weeds or they will suffer crop loss. There are over 30,000 weed species throughout the world and over 4,800 of these cause significant economic losses in production of food, feed, and fiber. (Howard 2009). Manual weeding is very laborious requiring to be repeated twice or three times before crop maturity. In large farms even with many labourers there is always the possibility of weed re-emergence before the entire farm is completed. Thus manual weeding is effective only for gardens and very small farms.

Chemical application has been very successful in weed control but must be applied in rationed proportions and spray characteristics. Specialized equipment is thus essential. In fact chemical application is the only fully mechanized farming operation. Developing spraying machines entails determining the nozzle characteristics as well as the pump discharge in order to ensure that desired application rate and coverage are not exceeded. Nozzle characteristics are first inferred from the spray pattern. Spray pattern refers to the regular form of the spray from the showerhead or nozzle, i.e. drenching rain, fine mist, sharp spray and massaging swirl spray patterns. Patternation is the measurement of uniformity and symmetry of the liquid distribution in a spray. Patternator is the instrument used to measure the spray distribution in a spray. Patternation can supply a quantitative measurement for the spray. The quantitative analysis of spray patterns is very important for nozzle design, selection and quality control, because the spray angle, the uniformity and the symmetry of the spray patterns are decisive parameters in practical applications. (Yang 2000).

A spray patternator is a device used to empirically determine the distribution (scatter or spread) of fluid from one or more spray nozzles. When one spray nozzle is used, there is a relatively even distribution of fluid on the spray surface. However, if two spray nozzles are used together such that there is an area of overlap, there will be a section of higher fluid concentration. This area of excess fluid is undesired because it results in increased costs and, in some cases, may be harmful to the environment. Therefore, it is desirable to locate an optimal spacing between the nozzles and a certain height from target so that the spray distribution is as uniform as possible and the overlap regions do not result in areas of high concentration, minimizing excess fluid.

A spray patternator consists of a table inclined at about ten degree divided into a number of grooved channels. The width of the channels is dependent upon the desired resolution of the spray distribution. Obviously, smaller channel width will produce higher resolution of the spray distribution. The spray nozzles are 
supported at regulated heights above the table and turned on. The nozzle location above the table will also affect the distribution of the spray so it is important to test the nozzles at different heights.

When the fluid reaches the table, it will be separated into the different channels and flow down the incline. When the fluid reaches the base of the table, each channel flows into its own graduated cylinder. The conventional spray patternator requires manual data acquisition. The person running the experiment must record the height of the water in each cylinder by reading the measurement in each graduated cylinder. Nozzle patternation was carried out for the Controlled Droplet Applicator (CDA) centrifugal disc nozzles before incorporation in the developed equipment.

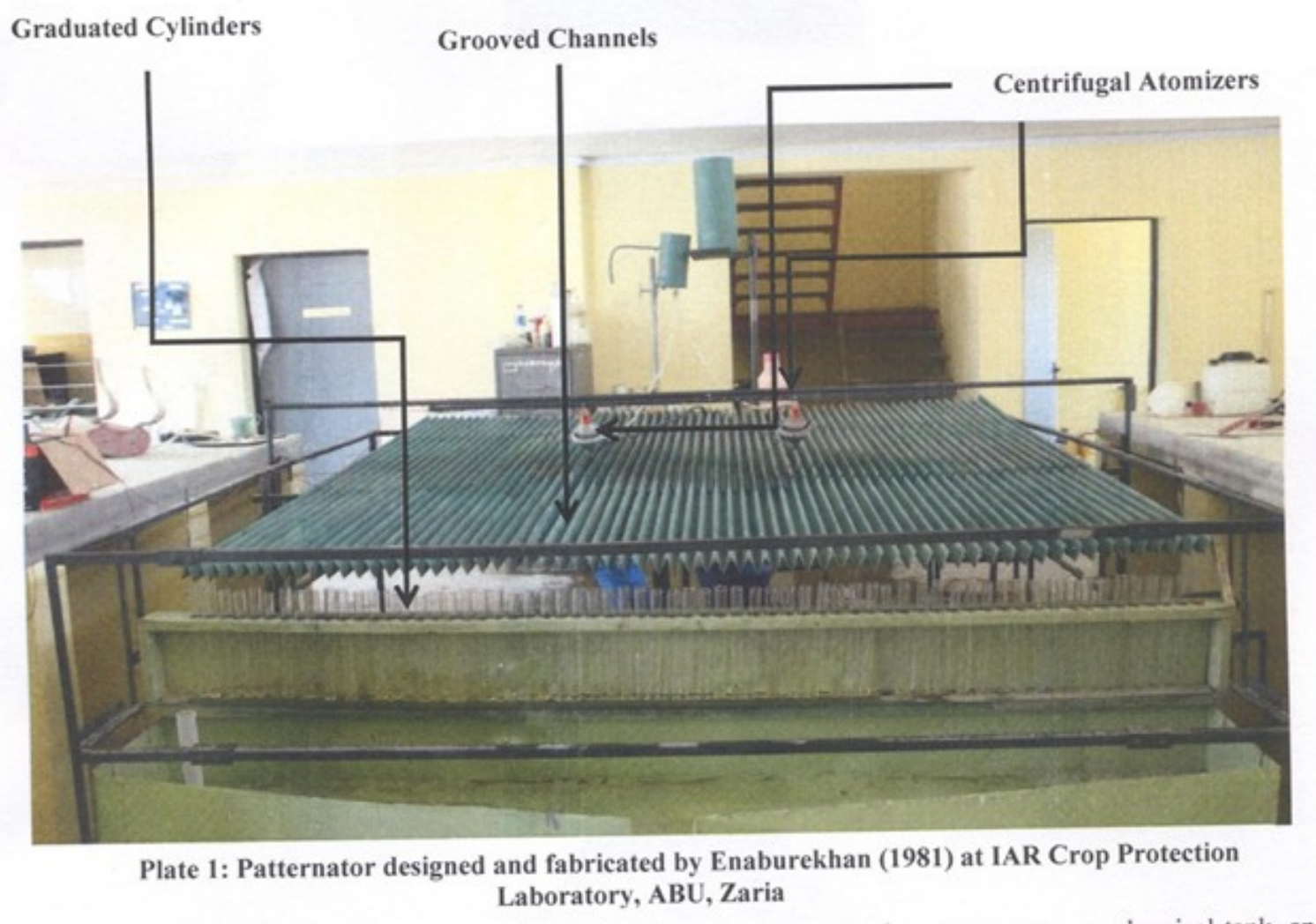

The equipment consists of a boom with four CDA atomizer nozzles, a gear pump, a chemical tank, and chair for an operator; all attached to a framework bolted to a rear axle. The wheels are spaced at $1.5 \mathrm{~m}$ to pass inbetween a specified number of ridges. The boom carrying several CDA atomizers is attached at the rear side of the framework. An attachment for the animal harness is installed at the front of the framework.

To achieve ground-metering of pesticide, the rear axle of a commonly used and serviceable vehicle (Land Rover) was employed. Plate 1 shows the machine. The motion of the axle flange is used to drive a hydraulic pump which pumps chemical to the nozzles. Ground-metering is achieved since whenever the assembly is in motion, the pesticide is pumped to the atomizers and when the pulling animals stop, pumping stops automatically. The framework in angular sections of medium carbon steel material carries the tank, pump and other appurtenances.

\section{Methodology}

The spray nozzles were tested on the Patternator and some characteristics were inferred. The patternator was narrow to permit full tests on more than one spinning disc but inference from the test was further confirmed by workshop test-run.

The machine was then constructed and reality tests were carried out to evaluate the conformity with design values. Manual rotation of the tire was used to determine spray parameters of pump discharge rate, nozzle flow rate at various heights as well as the swath. 


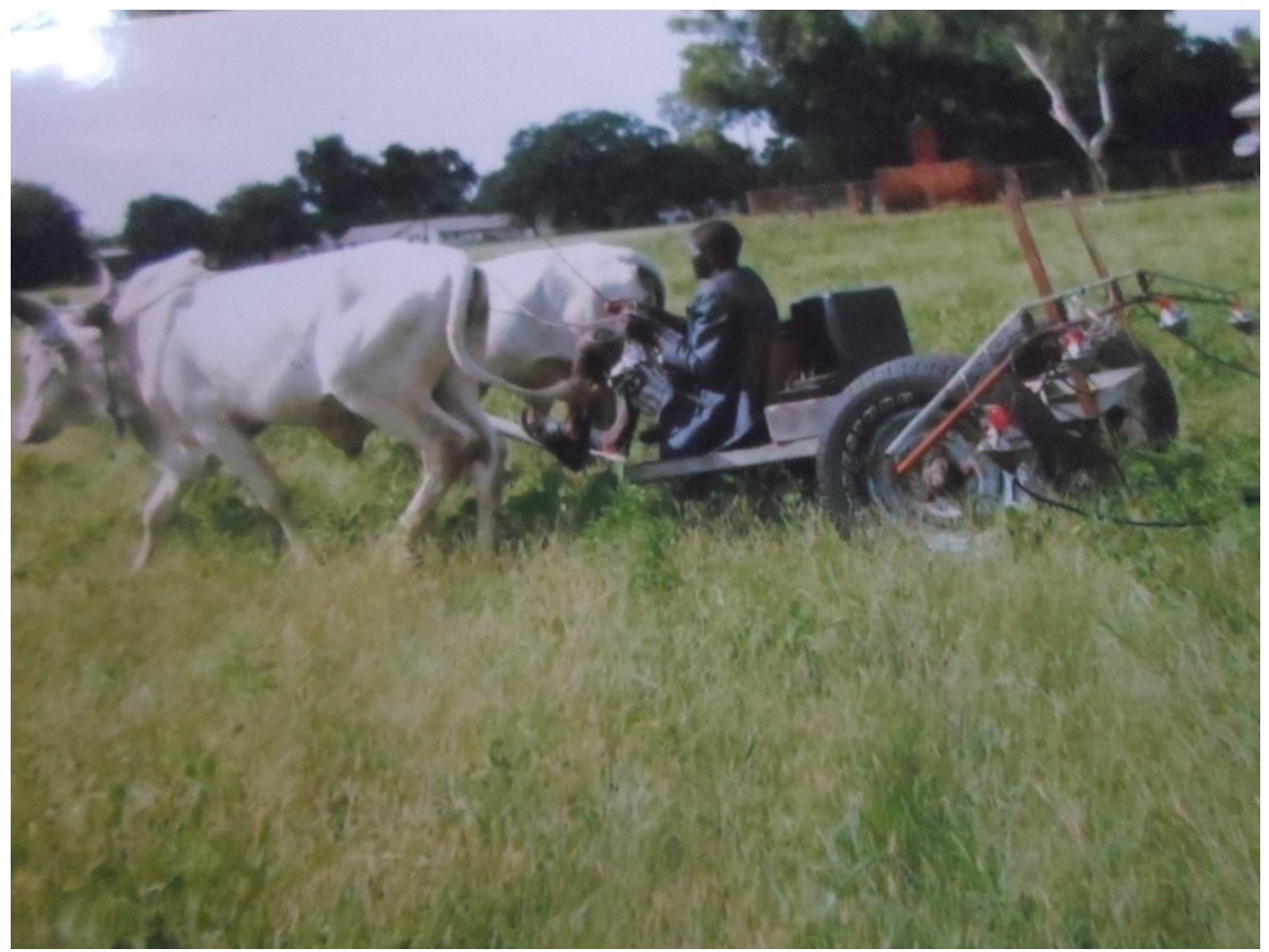

Plate: 2 Animal Drawn Ground Metered Shrouded Disc Sprayer during test-run

The equipment was then test run on the farm to determine the draft matching, the steering freeness as the work animals turn and also the water/chemical dispensed per hectare.

\section{Results}

\section{1: Laboratory Tests}

\subsection{1: Experimental Set-Up}

The experimental set-up consists of a patternator designed and fabricated by Enaburekhan (1981). It includes the following units: (a): Patternator table and stand (b): Tube rack (c): An adjustable boom to allow (d): Constant head supply (e): Liquid and electric lines. The table is made into $64 \mathrm{~V}$-shaped channels, $4 \mathrm{~cm}$ apart, $4.5 \mathrm{~cm}$ deep, with the sides $5 \mathrm{~cm}$ long at an angle of 45 degrees to the vertical. This patternator table is supported by a stand of dimensions $300 \mathrm{~cm} \times 300 \mathrm{~cm} \times 100 \mathrm{~cm}$.

The tube rack is also supported by this stand fixed $50 \mathrm{~cm}$ above the ground. It spans along the width of the channeled table, it is designed to hold the collecting tubes in position. A tube is kept directly under each channel on the sloping side of the patternator, so that, spray liquid falling on the patternator, is collected by the tubes.

Tests were carried for heights of $15 \mathrm{~cm}, 30 \mathrm{~cm}, 45 \mathrm{~cm}$ and $60 \mathrm{~cm}$ and for disc spacing not exceeding $70 \mathrm{~cm}$. Beyond $70 \mathrm{~cm}$, liquid flows out of the patternator as a result of the wider swath of the Micron Herbi disc atomizer. Further tests were done in the workshop to confirm theoretical swath. The Coefficient of Variation of Readings of spray volume distribution patterns obtained from Patternator experiments at various boom heights and discs' spacing are summarized in Table 1.

Table 1: Coefficient of Variation for Patterns obtained from Different Boom Height at Various Disc Spacing.

\begin{tabular}{|c|c|c|c|}
\hline \multirow{2}{*}{$\begin{array}{c}\text { Boom Height } \\
(\mathrm{cm})\end{array}$} & \multicolumn{3}{|c|}{$\begin{array}{c}{[* \text { Disc Spacing (cm)] }} \\
\text { Coefficient of Variation COV }(\%)\end{array}$} \\
\cline { 2 - 4 } & {$[* 30]$} & {$[* 40]$} & {$[* 70]$} \\
\hline 15 & 92 & 66 & 50 \\
\hline 30 & 78 & 62 & 68.5 \\
\hline 45 & 73 & 71.9 & 79.2 \\
\hline 60 & 84 & 80 & \\
\hline
\end{tabular}

Observation shows there is decrease in Coefficient of Variation with increase in disc spacing. For the $40 \mathrm{~cm}$ and $70 \mathrm{~cm}$ disc spacing, the height above Patternator of $30 \mathrm{~cm}$ is optimum. The best pattern is seen to occur at this height with disc spacing of $70 \mathrm{~cm}$. The spray overlap was recorded at $16.6 \%$ of single nozzle swath. 


\section{2: Workshop Tests}

\subsection{1: Pump Discharge Rate \\ a. Procedure}

One of the tires was fixed ensuring that rotation of one tire turns the axle shaft which in turn rotates the pump pulley. The free tire was manually rotated during one minute. The pump discharge per minute and the number of revolutions were recorded for water and for Glyphosate plus water in two different ratios, in three replications.

\section{b. Results}

Table 2: Pump Discharge at various tire-revolutions using Water as test fluid

\begin{tabular}{|c|c|c|}
\hline & Discharge rate (ml/min) & Revolution \\
\hline 1. & $\mathbf{7 6 0}$ & $\mathbf{3 0}$ \\
\hline 2. & $\mathbf{7 4 0}$ & $\mathbf{2 7}$ \\
\hline 3. & $\mathbf{7 6 0}$ & $\mathbf{2 8}$ \\
\hline Average & $\mathbf{7 5 3 . 3}$ & $\mathbf{2 8 . 3}$ \\
\hline
\end{tabular}

Table 3: Pump Discharge at various tire-revolutions using Water/ Glyphosate (2:1) as test fluid

\begin{tabular}{|c|c|c|}
\hline & Discharge rate (ml/min) & Revolution \\
\hline 1. & 780 & 30 \\
\hline 2. & 720 & 28 \\
\hline 3. & 710 & 28 \\
\hline Average & 736.6 & 29 \\
\hline
\end{tabular}

Table 4: Pump Discharge at various tire-revolutions using Water/ Glyphosate (3:1) as test fluid

\begin{tabular}{|c|c|c|}
\hline & Discharge rate $(\mathrm{ml} / \mathrm{min})$ & Revolution \\
\hline 1. & 740 & 28 \\
\hline 2. & 720 & 30 \\
\hline 3. & 716 & 30 \\
\hline Average & 725.3 & $\mathbf{2 9 . 3}$ \\
\hline
\end{tabular}

Result implies that at both the lower and the higher averages for Water/Glyphosate of 29.3Rpm and 0.7253 litres $/ \mathrm{min}$; and Water/Glyphosate of $29 \mathrm{Rpm}$ and $0.7366 \mathrm{litres} / \mathrm{min}$, a speed of at least $17 \mathrm{Rpm}$ is required for the pump to deliver the needed volume.

\subsection{2: Nozzle Flow rate}

a. Procedure

One of the tires was fixed ensuring that rotation of one tire turns the axle shaft which in turn rotates the pump pulley. The free tire was continuously rotated for five minutes. Water was used as the test fluid. The discharges from each of the nozzles at different heights were collected in polythene sacks. The discharges were measured and divided by 5 to get the value in (litre/min). The experiment was also conducted for water and for glyphosate plus water.

\section{b. Results for water as Test Fluid}

Table 5: Nozzle (red restrictor) Discharge (1/min), at $15 \mathrm{~cm}$ Height.

\begin{tabular}{|c|c|c|c|}
\hline Nozzle 1 & Nozzle 2 & Nozzle 3 & Nozzle 4 \\
\hline $\mathbf{5 4 0}$ & $\mathbf{5 5 0}$ & $\mathbf{5 2 0}$ & $\mathbf{5 8 0}$ \\
\hline $\mathbf{5 4 6}$ & $\mathbf{5 3 4}$ & $\mathbf{5 3 8}$ & $\mathbf{5 4 0}$ \\
\hline $\mathbf{5 1 8}$ & $\mathbf{5 2 0}$ & $\mathbf{5 3 6}$ & $\mathbf{5 1 0}$ \\
\hline Av:534.6 & $\mathbf{5 3 7 . 3}$ & $\mathbf{5 3 1 . 3}$ & $\mathbf{5 4 3 . 3}$ \\
\hline
\end{tabular}

Table 6: Nozzle (red restrictor) Discharge (1/min), at $30 \mathrm{~cm}$ Height.

\begin{tabular}{|c|c|c|c|}
\hline Nozzle 1 & Nozzle 2 & Nozzle 3 & Nozzle 4 \\
\hline 500 & 520 & 560 & 540 \\
\hline 526 & 540 & 530 & 510 \\
\hline S16 514 & 534 & 510 & 508 \\
\hline
\end{tabular}

Table 7: Nozzle (red restrictor) Discharge (1/min), at $45 \mathrm{~cm}$ Height.

\begin{tabular}{|c|c|c|c|}
\hline Nozzle 1 & Nozzle 2 & Nozzle 3 & Nozzle 4 \\
\hline $\mathbf{5 4 0}$ & $\mathbf{5 6 0}$ & $\mathbf{5 2 0}$ & 526 \\
\hline 525 & 526 & 538 & 540 \\
\hline 540 & 530 & 534 & 546 \\
\hline Av: 536 & 538.6 & 530.6 & 535.3 \\
\hline
\end{tabular}


Table 8: Nozzle (red restrictor) Discharge ( $1 / \mathrm{min})$, at $60 \mathrm{~cm}$ Height.

\begin{tabular}{|c|c|c|c|}
\hline Nozzle 1 & Nozzle 2 & Nozzle 3 & Nozzle 4 \\
\hline $\mathbf{5 3 0}$ & $\mathbf{5 4 0}$ & $\mathbf{5 6 0}$ & $\mathbf{5 1 0}$ \\
\hline $\mathbf{5 3 8}$ & $\mathbf{5 1 0}$ & $\mathbf{5 4 0}$ & $\mathbf{5 3 8}$ \\
\hline $\mathbf{5 2 6}$ & $\mathbf{5 3 6}$ & $\mathbf{5 1 8}$ & $\mathbf{5 3 0}$ \\
\hline Av:531.3 & $\mathbf{5 2 1 . 3}$ & $\mathbf{5 3 9 . 3}$ & $\mathbf{5 2 6}$ \\
\hline
\end{tabular}

c. Results for Test Fluid: Glyphosate + Water (Ratio-1:2); Nozzle: Red.

Table 9: Height: $15 \mathrm{~cm}$ (Discharge 1/min)

\begin{tabular}{|c|c|c|c|}
\hline Nozzle 1 & Nozzle 2 & Nozzle 3 & Nozzle 4 \\
\hline 104 & 103 & 100 & 103 \\
\hline 103 & 104 & 102 & 103 \\
\hline 122 & 100 & 103 & 104 \\
\hline Av:109.6 & 102.3 & 101.6 & 103.3 \\
\hline
\end{tabular}

Table 10: Height: 30cm (Discharge $1 / \mathrm{min})$

\begin{tabular}{|c|c|c|c|}
\hline Nozzle 1 & Nozzle 2 & Nozzle 3 & Nozzle 4 \\
\hline 103 & 102 & 100 & 100 \\
\hline 100 & 103 & 103 & 102 \\
\hline 102 & 100 & 100 & 100 \\
\hline Av:101.6 & 101.6 & 101 & 100.6 \\
\hline
\end{tabular}

Table 11: Height: $45 \mathrm{~cm}$ (Discharge 1/min)

\begin{tabular}{|c|c|c|c|}
\hline Nozzle 1 & Nozzle 2 & Nozzle 3 & Nozzle 4 \\
\hline 92 & 100 & 105 & 100 \\
\hline 100 & 103 & 105 & 104 \\
\hline 100 & 102 & 100 & 103 \\
\hline Av:97.6 & 101.6 & 103.3 & 102.3 \\
\hline
\end{tabular}

Table 12: Height: 60cm (Discharge 1/min)

\begin{tabular}{|c|c|c|c|}
\hline Nozzle 1 & Nozzle 2 & Nozzle 3 & Nozzle 4 \\
\hline 100 & 100 & 100 & 100 \\
\hline 103 & 106 & 100 & 103 \\
\hline 102 & 100 & 95 & 102 \\
\hline Av:101.6 & 102 & 98.3 & 101.6 \\
\hline
\end{tabular}

\subsection{3: Measurement of Swath Width of Prototype at Various Boom Heights}

a. Procedure: One of the tires was fixed ensuring that rotation of one tire turns the axle shaft which in turn rotates the pump pulley. The nozzles were started from the battery while the free tire was rotated continuously. The marks on the ground made by the sprayed water were measured at various heights to get the swath widths.

Table 13: Swath at Various boom Heights

\begin{tabular}{|c|c|}
\hline Boom Height (cm) & Swath width (cm) \\
\hline 15 & 547 \\
\hline 30 & 560 \\
\hline 45 & 583 \\
\hline 60 & 595 \\
\hline
\end{tabular}

\section{4: Coefficient of Variation Computation}

Nodby (1978) suggested that atomizers should be evaluated on the basis of their co-efficient of variation and he introduced the following grading in determining usability of nozzles. From the table if the coefficient of variation obtained is less than $10 \%$ the spray distribution is classified particularly good and when it is between $10 \%$ and $12 \%$ is very good, between 12 and 16 satisfactory and between $16 \%$ to $20 \%$ and above the spray is termed unusable. (BabaShani et al 2013).

The Coefficient of Variation is expressed as the ratio of standard deviation and mean. It is often abbreviated as CV. Coefficient of variation is the measure of variability of the data. When the value of coefficient of variation is higher, it means that the data has high variability and less stability.

Table 14: Suggested grades of Atomizers by Nodby 1978

\begin{tabular}{|c|c|}
\hline $\begin{array}{c}\text { Co-efficient of variation } \\
(\%)\end{array}$ & Grade \\
\hline$<10$ & Particularly Good \\
\hline $10-12$ & Very Good \\
\hline $12-16$ & Satisfactory \\
\hline $16-20$ & Unusable \\
\hline$>20$ & Unusable \\
\hline
\end{tabular}


When the value of coefficient of variation is lower, it means the data has less variability and high stability. Mathematically, the coefficient of variation is the estimated standard deviation (an absolute Measure).The formula for coefficient of variation is given as:

\section{$\mathrm{CV}=\mathrm{SD} /$ Mean $x 100$----- (1)(GREEFF 2006)}

\section{Where $\mathbf{C V}=$ Coefficient of Variation,}

\section{SD $=$ Standard Deviation}

The Coefficient of Variation of the readings for the test reported by Tables 9 to 12, were computed to find the most suitable height. The calculations are given hereunder in Tables 15 to 18. Calculation shows that at any of the heights, the nozzles are particularly good but the best height is at $30 \mathrm{~cm}$ above the ground. The boom was set at this height with a swath of $560 \mathrm{~cm}$.

Table 15: CV at Height $15 \mathrm{~cm}$

\begin{tabular}{|c|c|c|c|c|}
\hline No. & $\mathrm{X}$ & $\mathrm{M}$ & $\mathrm{X}-\mathrm{M}$ & $(\mathrm{X}-\mathrm{M})^{2}$ \\
\hline 1. & 109.6 & 104.2 & 5.4 & 29.16 \\
\hline 2. & 102.3 & 104.2 & -1.9 & 3.61 \\
\hline 3. & 101.6 & 104.2 & -2.6 & 6.76 \\
\hline 4. & 103.3 & 104.2 & -0.9 & 0.81 \\
\hline & & & Total & 40.3 \\
\hline
\end{tabular}

Standard deviation $=\mathbf{6 . 3 5}$

Coefficient of Variation $=6.35 / 104.2 \times 100$

$=6$.

Table 16: CV at Height $30 \mathrm{~cm}$

\begin{tabular}{|c|c|c|c|c|}
\hline No. & $\mathrm{X}$ & $\mathrm{M}$ & $\mathrm{X}-\mathrm{M}$ & $(\mathrm{X}-\mathrm{M})^{2}$ \\
\hline 1. & 101.6 & 101.2 & 0.4 & $\mathbf{0 . 1 6}$ \\
\hline 2. & 101.6 & 101.2 & 0.4 & $\mathbf{0 . 1 6}$ \\
\hline 3. & 101 & 101.2 & -0.2 & 0.04 \\
\hline 4. & 100.6 & 101.2 & -0.6 & 0.36 \\
\hline & & & Total & 0.72 \\
\hline
\end{tabular}

Standard deviation $=0.84$

Coefficient of Variation $=0.84 / 101.2 \times 100$

$=\mathbf{0 . 8 3}$

Table 17: CV at Height $45 \mathrm{~cm}$

\begin{tabular}{|c|c|c|c|c|}
\hline No. & $\mathrm{X}$ & $\mathrm{M}$ & $\mathrm{X}-\mathrm{M}$ & $(\mathrm{X}-\mathrm{M})^{2}$ \\
\hline 1. & 97.6 & 101.2 & -3.6 & 12.96 \\
\hline 2. & 101.6 & 101.2 & 0.4 & 0.16 \\
\hline 3. & 103.3 & 101.2 & 2.1 & 4.41 \\
\hline 4. & 102.3 & 101.2 & 1.1 & 1.21 \\
\hline & & & Total & 18.74 \\
\hline
\end{tabular}

Standard deviation $=\mathbf{4 . 3 2}$

Coefficient of Variation $=4.32 / 101.2 \times 100$

$=4.3$.

Table 18: CV at Height $60 \mathrm{~cm}$

\begin{tabular}{|c|c|c|c|c|}
\hline No. & $\mathrm{X}$ & $\mathrm{M}$ & $\mathrm{X}-\mathrm{M}$ & $(\mathrm{X}-\mathrm{M})^{2}$ \\
\hline 1. & 101.6 & 100.9 & 0.7 & $\mathbf{0 . 4 9}$ \\
\hline 2. & 102 & 100.9 & 1.1 & 1.21 \\
\hline 3. & 98.3 & 100.9 & -2.6 & 6.67 \\
\hline 4. & 101.6 & 100.9 & 0.7 & 0.49 \\
\hline & & & Total & 8.95 \\
\hline
\end{tabular}

Standard deviation $=2.99$

Coefficient of Variation $=2.99 / 100.9 \times 100$

$=2.96$.

\section{Conclusion}

Above steps were dutifully followed in the parametric determination of spray component characteristics before final integration into the constructed equipment.

The machine was constructed using the Centrifugal Disc Applicator nozzles that were tested. The boom was installed at the optimum height of $30 \mathrm{~cm}$ with swath width of $560 \mathrm{~cm}$. It was tested on a $50 \mathrm{~m} \times 29 \mathrm{~m}$ farm area at the premises of Institute for Agricultural Research, Ahmadu Bello University Zaria (Plate 2); and the 
sprayingat the said boom height was found to be very efficient. Water/glyphosate ratio of 3:1 was employed and resulted in Application Rate of 8.62litres of Glyphosate per hectare.

\section{References}

[1]. Yang Cao (2000).The Image Analysis for Optical Spray Patternation. National Library of Canada, 0-612-55892-2; pp. 8.

[2]. Howard G. A. L (2009). Guide to Effective Weed Control. Oklahoma Cooperative Extension Service PSS-2750 pp. 1.

[3]. BabaShani B, Mohammed U. S. and Abubakar L. G (2013). Animal Drawn Sprayer Distribution Pattern. Applied Science Reports 1 (3); pp. 72.

[4]. Johan Greeff (2006). Coefficient of Variation of Wool Fibre Diameter in Merino Breeding Programs. Farm Note 46/98 of Great Southern Agricultural Research Institute, Katanning, Western Australia; pp.

\section{AUTHORS' PROFILE}

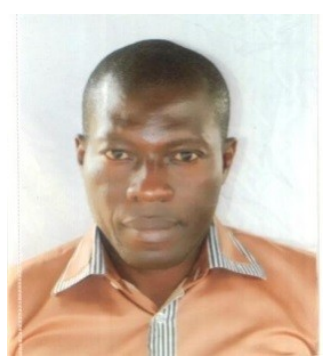

Engr. Mike Amonye, MNSE; hails from Obosi in Anambra State of Nigeria and holds a Bachelor of Engineering Degree from the University of Benin, Benin City, Nigeria. He is a postgraduate student of Farm Power \& Machinery at the Department of Agricultural Engineering, Ahmadu Bello University, Zaria, Nigeria. $\mathrm{He}$ is the Head of Department, Manufacturing Services at Hydraulic Equipment Development Institute, Federal Ministry of Science \& Technology, Kano.

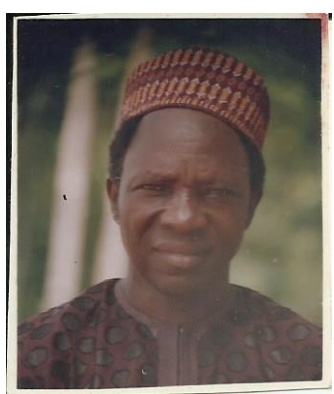

Prof. M. L. Suleiman is a professor of Agric. Power \& Machinery Engineering at the Ahmadu Bello University, Zaria, Nigeria. He holds a Bachelor of Engineering Degree (B. Eng.) in Agricultural Engineering from Ahmadu Bello University Zaria, in 1977; MSc in Agric. Machinery Engineering from Cranfield University; UK, England in 1983 and PhD in Agric. Power \& Machinery Engineering from Ahmadu Bello University in 1994. He is a Crop Protection Specialist and the first supervisor of the project.

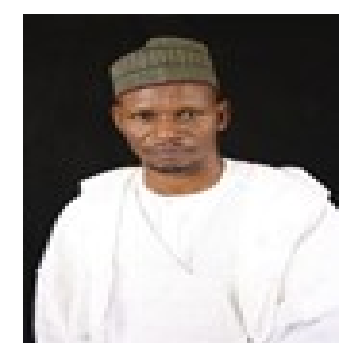

Abdullahi El-Okene Born in Okene, Nigeria on Thursday 6th, June 1957, and has a Bachelor's degree in Engineering from Ahmadu Bello University, Nigeria in 1979, M.Sc in 1984 and PhD in1995. He is currently Professor of Agricultural Engineering and heads the Agricultural Mechanization Research Programme. He is the second supervisor of the project. 


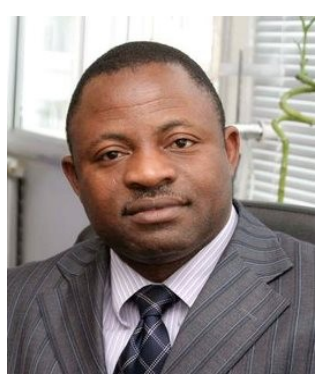

Engr. Dr. Ibrahim O. Abdulmalik hails from Okene, Kogi State, Nigeria. He holds PGD and Master's Degree in Mechanical/Production Engineering from NnamdiAzikiwe University, Awka in 2004 and 2005 respectively; and PhD in Manufacturing Strategy from London South Bank University, UK, England in 2010. He is presently the Acting Director of Hydraulic Equipment Development Institute, Federal Ministry of Science \& Technology, Kano, Nigeria, a research institute mandated to develop hydraulic and pneumatic devices and equipment. 